\title{
CARDIOVASCULAR DISEASES IN THE BRITISH ARMY OVERSEAS
}

\author{
BY \\ RAYMOND A. MOIR AND K. SHIRLEY SMITH \\ From various Military Hospitals in the Mediterranean Theatre \\ Received March 1, 1946
}

The writers of the present communication have, during three years with British Military Hospitals in North Africa, Greece, and Italy, dealt with very large numbers of sick. In a certain period of 27 months, 9824 in-patients came under the charge of one of us (K.S.S.), while during a period of 23 months the other (R.A.M.) has examined 1431 outpatients. As we have both been impressed by the infrequency of cardiovascular disease and disorder, particularly in contrast with the incidence in the First World War, we have undertaken a survey of the number and varieties of these conditions in each of these groups.

\section{Material ANd Period of Survey}

Upwards of 11,000 patients have been observed in more than one hospital, but in no case was the hospital one to which cardiovascular cases were specially directed. During the 8-months' period from April to November 1944 there was another hospital in the vicinity at which electrocardiographic examination was available, but the quarterly returns showed that this caused no alteration of the average incidence of cardiovascular disorders among our patients. Our figures are therefore derived from unselected sources. Moreover, as there is no kind of heart disease or disorder in which climate or other regional variable would be likely to influence incidence in adults, the figures are probably representative of the general incidence in the British Army overseas. Foreign service in itself might be regarded as an influence favouring functional cardiovascular disorder so that our figures are possibly not representative of the British Army as a whole.

The patients with which this survey is specially concerned are those afflicted with primary organic heart disease such as mitral stenosis, or syphilitic aortitis, and those with functional disorders such as effort syndrome or vaso-vagal syncope. A further group necessarily came under consideration; these were the patients with cardiac disorders due to some underlying non-cardiac disease. Conditions under this heading were the acute myocarditis of diphtheria, and the acute left ventricular failure sometimes seen in acute nephritis. Lesions partly arterial or venous, such as trench-feet or thrombo-phlebitis, have been excluded from this survey. Typhus, in spite of its impact upon the cardiovascular system, has also been excluded.

The period which has come under consideration for in-patients is that from July 1, 1943, to September 30, 1945-27 months. The first six months of 1943 were exceptional in that the hospital organization was overburdened with great numbers of battle casualties and the large influx of those sick with malaria and dysentery. These circumstances, although they would lend additional point to our figures, have led us to start the survey from July 1943 . The period over which the 1431 out-patients have been seen is from December 1942 to November 1943 and from November 1944 to November 1945.

\section{OBSERVATIONS}

The Table shows the numbers of cases of various diseases and disorders occurring in each period of 12 and 15 months. It will be seen that among a total of 9824 in-patients there were only 42 cases of organic cardiovascular diseases and 23 cases of functional circulatory 
disorders. The total of 65 patients represents an incidence of 0.66 per cent. There were, in all, 5 patients with cardiac disorders secondary to diphtheria or nephritis, and if these be included the total is 70 patients, an incidence of 0.71 per cent.

An analysis of the 42 patients with organic disease shows rather more than half (23) to be hypertensive or degenerative, rather less than a third (13) rheumatic, 3 syphilitic, and 1

TABLE

Incidence of Cardiovascular Disorders at British Military Hospitals in the Mediterranean Theatre

\begin{tabular}{|c|c|c|c|c|c|c|}
\hline \multirow{2}{*}{ Diagnosis } & \multicolumn{3}{|c|}{ In-patients (9824) } & \multicolumn{3}{|c|}{ Out-patients (1431) } \\
\hline & $\begin{array}{c}\text { July } 1,1943 \text {, to } \\
\text { June } 30,1944\end{array}$ & $\begin{array}{c}\text { July } 1,1944 \text {, to } \\
\text { Sept. } 30,1945\end{array}$ & & $\begin{array}{l}\text { Dec. } 1942 \text { to } \\
\text { Nov. } 1943\end{array}$ & $\begin{array}{l}\text { Nov. } 1944 \text { to } \\
\text { Nov. } 1945\end{array}$ & \\
\hline $\begin{array}{ll}\text { Effort syndrome } & \ldots \\
\text { Vaso-vagal syncope } & \ldots \\
\text { Paroxysmal tachycardia } & \ldots \\
\text { Left mammary pain } & \ldots\end{array}$ & $\begin{array}{l}9 \\
4 \\
2 \\
0\end{array}$ & $\begin{array}{l}2 \\
4 \\
0 \\
2\end{array}$ & & $\begin{array}{r}17 \\
0 \\
0 \\
3\end{array}$ & $\begin{array}{l}4 \\
0 \\
0 \\
2\end{array}$ & \\
\hline Total " functional ". & 15 & 8 & $=23$ & 20 & 6 & $=26$ \\
\hline 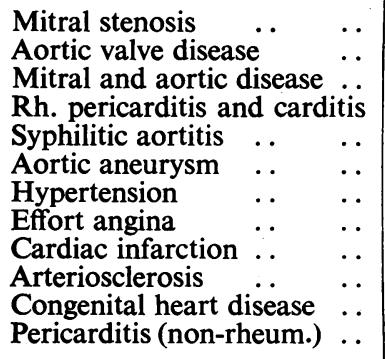 & $\begin{array}{l}3 \\
1 \\
1 \\
0 \\
0 \\
0 \\
6 \\
0 \\
0 \\
2 \\
0 \\
0\end{array}$ & $\begin{array}{l}2 \\
4 \\
1 \\
1 \\
2 \\
1 \\
9 \\
2 \\
4 \\
0 \\
1 \\
2\end{array}$ & & $\begin{array}{l}2 \\
0 \\
1 \\
0 \\
1 \\
0 \\
3 \\
0 \\
1 \\
0 \\
1 \\
0\end{array}$ & $\begin{array}{l}1 \\
0 \\
0 \\
0 \\
1 \\
0 \\
1 \\
0 \\
0 \\
0 \\
0 \\
0\end{array}$ & \\
\hline Total " organic" (primary) & 13 & 29 & $=42$ & 9 & 3 & $=12$ \\
\hline $\begin{array}{ccc}\text { Diphtheritic myocarditis } & \\
\text { Left ventricular failure } & \text { in } \\
\text { nephritis } & \ldots & \ldots\end{array}$ & $\begin{array}{l}1 \\
2\end{array}$ & $\begin{array}{l}2 \\
0\end{array}$ & & - & - & \\
\hline Total " organic" (secondary) & 3 & 2 & $=5$ & - & 一 & - \\
\hline \multicolumn{2}{|l|}{ Total all cardiovascular- } & \multicolumn{2}{|c|}{ In-patients } & \multicolumn{3}{|c|}{$=38$} \\
\hline \multicolumn{2}{|l|}{ Total all patients of same period } & \multicolumn{2}{|c|}{ (I.P.) } & (O.P.) & \multicolumn{2}{|l|}{$=1431$} \\
\hline \multicolumn{2}{|c|}{ Cardiovascular cases: percentage of total } & \multicolumn{2}{|c|}{$=0.7$} & (O.P.) & \multicolumn{2}{|l|}{$=2 \cdot 7$} \\
\hline
\end{tabular}

congenital. The remaining 2 were cases of non-rheumatic pericarditis. Of the 23 functional cases, half (11) suffered from effort syndrome, 8 from vaso-vagal syncope, 2 from paroxysmal tachycardia, and 2 from left mammary pain.

A further analysis of these figures in terms of incidence earlier or later in the 27 months is of interest. A dividing line at June 30, 1944, gives a total of 5740 patients under review before and 4084 after this date. During the earlier period there were 15 cases of functional and 8 of organic disease; whereas during the later period there were only 8 cases of functional disorder compared to 29 patients with organic disease.

The second part of the table shows the occurrence of cardiovascular disorders among outpatients during two periods; the first from December 1942 to November 1943, the second from November 1944 to November 1945. In the first period, of a total of 1125 cases, only 29 (2.5 per cent) suffered from cardiac syndromes. In the second period, the incidence was 9 out of 306 patients ( 3.0 per cent). This total of 38 patients represents a percentage of 2.7 per cent. The difference in the total numbers seen in the two periods is due to the fact that during the first period a number of Infantry and General Reserve training depots were in the neighbourhood. 


\section{CARDIOVASCULAR DISEASES IN THE BRITISH ARMY OVERSEAS}

In the first period, 20 were functional and 9 organic, and in the second period, 6 were functional and 3 organic - thus in each group two-thirds of the patients had functional disorders. Clearly the somewhat higher incidence of cardiac disorders in out-patients as compared with in-patients is accounted for by the greater numbers of functional disorders not requiring admission in this class of patient.

\section{COMMENTS AND Discussion}

The most remarkable thing about the figures in general is that they are so low. More conspicuous still is the infrequency of functional cardiovascular disorders; a total of 49 among 11,255 in- and out-patient sick is astonishingly small when it is remembered that in the war of 1914-18 disturbance of the cardiovascular system was of major importance-one case being observed for every four men wounded-and the group as a whole being second in dimensions only to pulmonary diseases among medical disorders (Lewis, 1940).

Lewis also states that 70,000 men had reported sick and been classed as cardiovascular by the summer of 1918. Among pensioners were 44,000 cases of "effort syndrome." The official history of the Great War gives 36,569 as the number of men discharged from the Army and Navy, up to May 1918, on account of cardiovascular disorders; it also claims that the true numbers of those reporting sick with cardiac symptoms must have been much in excess of Lewis' calculation of 70,000.

That functional disorders exceeded the organic during the war of 1914-18 was also indicated by the figures of Parkinson (1916). Among 90 consecutive soldiers reporting sick with symptoms suggestive of heart disease at a Casualty Clearing Station 28 had organic disease (almost all valvular) compared with 40 with "so-called soldier's heart." The remaining 22 cases were non-cardiac.

Wood (1941), investigating these cases at an Effort Syndrome Unit, referred to the fact that there were but two special centres in England and one in Scotland; working at the largest of these he had dealt with no more than 700 during the first 20 months of the war. In the Middle East Force, from 1941 onwards, all cases of effort syndrome were sent to one centre for disposal. At this centre 338 cases were observed by Hill and Dewar (1945) between July 1941 and February 1945.

The few cases of functional disorder dealt with in hospital in the present series show that medical officers are alive to the fact that patients with symptoms of this kind do not respond well to treatment as in-patients, and may be even the worse for it. Doubtless, the increased understanding of the psychogenic basis of this disorder has enabled doctors, at all stages in the soldier's career, to avoid fanning the spark of their malady into the full flame of a doctor-made disorder. The diminishing number of these cases with the passage of time may be due to the fact that the initial conditions of active service would be more likely to produce this type of psychosomatic response, and also to the increasing awareness of medical officers of the correct disposal of such cases as they developed.

To the small number of patients with cardiac neurosis must be added a considerable number who broke down with its counterpart in other systems. It may be that the numbers treated for " exhaustion" at forward centres and invalided on the score of anxiety state and psychopathic personality far exceeded any corresponding groups in the war of 1914-18.

The rising incidence of organic disease contrasted with the diminishing frequency of the functional; although the second (later) period under review comprised substantially fewer patients (4084 to 5740) there was a more than threefold increase in cases of organic cardiovascular disease. This trend suggests that with the prolongation of the war to three, four, and five years, hypertensive and degenerative changes had time to develop as a result of continuing stress and strain in those constitutionally prone to them; at the same time, the army of this later stage will have comprised a greater proportion of men in the higher agegroups.

A few general comments follow.

(1) The remarkable low incidence of cardiovascular disorders in the Army (less than 7 per 1000 of all sick admitted to hospital) reflects much credit on Recruiting Medical Boards who succeeded in eliminating at this stage the vast majority of patients with organic cardiovascular disease and to a large extent weeding out those prone to effort syndrome and other 
neuro-circulatory upsets. Analysis of effort syndrome cases of 1914-18 showed that 43 per cent had had symptoms on enlistment (Lewis, 1940).

(2) A total of 17 cases of rheumatic heart disease was a very small number. These cases are generally not hard to detect at routine recruiting examinations. The cases encountered in this series no doubt included some whose signs were very slight two or three years previously when they joined up. The physical stress of army life and campaigning might be expected to accelerate the natural diminution of the cardiac reserve. A majority of the patients with rheumatic valvular disease presented with gradually increasing breathlessness on exertion.

(3) Apart from the low incidence of rheumatic heart disease, the incidence of acute infective polyarthritis of all types was astonishingly low when the living conditions of the men are remembered (only 62 cases, or 0.6 per cent of all in-patients). Both in the winter and spring of 1943 in North Africa, and in the same seasons in Italy in 1944, the front-line soldiers were subjected to prolonged exposure to wet and cold. Among the very few acute arthritic illnesses encountered there was only one case in which valvular disease developed in a heart believed to be previously healthy. In this man of 24 years acute polyarthritis was succeeded by pericarditis and thereafter an aortic diastolic murmur was heard for the first time.

(4) Only two cases of congenital disease were encountered. The first was an unobtrusive one, and a condition (dextrocardia) that might easily be passed over among large numbers of examinees, and it might be added, appropriately so. The second was pulmonary stenosis with few signs that may well have progressed under active service conditions.

(5) Certain cardiac disorders secondary to diseases which are not uncommon have a special significance in active service conditions.

(a) Diphtheria. This disease is common in the army overseas. Fortunately, acute diphtheritic myocarditis is a rare event owing to the insistence among medical officers on large and early dosage with anti-diphtheritic serum even in suspected cases, and appreciation of the paramount necessity for at least four weeks rest in bed. Special risks exist in that diphtheritic infection of septic sores or abrasions carry the same threat to the heart as faucial infections but are more insidious in their development of circulatory and neuritic complications and are more likely to escape correct diagnosis. For example, during active operations a patient may be admitted for treatment of injuries the severity and priority of which detract attention from an indolent painless sore in which diphtheritic infection has supervened, until myocarditis or neuritis are far advanced.

(b) Acute nephritis. It is well known that acute left ventricular failure with paroxysmal nocturnal dyspnœa sometimes develops in the course of acute nephritis, particularly when the hypertension is conspicuous or sustained. This complication has twice been encountered in the present series, in patients with acute nephritis whose principal complaint was waking in the night short of breath. The onset with this symptom might be related to the more strenuous life of the average soldier compared with the average civilian.

(6) During the period under review the number of in-patients with lobar or bronchopneumonia was 100 . It is known from morbid histological studies that myocarditis may complicate these diseases (but not primary atypical pneumonia). However, in no case was there evidence either of myocarditis or of right heart failure. Nor did secondary pericarditis ever develop. This result is surprising when the conditions under which they were taken ill, and the consequent likelihood of a severe infection, are borne in mind.

(7) Certain unusual conditions may be contingent on active service. For example, in 1943 in North Africa when prophylactic mepacrine was first instituted, a medical officer developed auricular fibrillation in the course of gastro-enteritis that followed the third dose of $0.2 \mathrm{~g}$., the doses being at 4-day intervals. After some hours the arrhythmia disappeared. The patient had a healthy heart, and he has had no such disturbances in the two years that have since elapsed.

\section{SUMMARY}

An investigation has been made of the incidence of cardiovascular disorders among British soldiers overseas. 


\section{CARDIOVASCULAR DISEASES IN THE BRITISH ARMY OVERSEAS}

A survey of 9824 consecutive admissions to a Medical Division, and of 1431 consecutive soldiers attending an out-patients' clinic, has been made.

Among the 9824 in-patients there were 70 cases of functional or organic cardiovascular disorder, an incidence of only 0.71 per cent. The organic disorders were about twice as frequent as the functional. During the later part of the 27-months' period, there was an increasing ratio of organic to functional disorder.

A total of 38 patients with cardiovascular disorders were observed among the 1431 outpatients $(2 \cdot 7$ per cent). Approximately two-thirds of these patients had functional conditions and one-third organic lesions.

Effort syndrome never represented an important medical disability owing to (i) efficient selection by Recruiting Medical Boards, and (ii) better understanding of the appraisal and disposal of cases at their inception by army medical officers. The infrequency of effort syndrome contrasted sharply with its high incidence in the war of 1914-18.

Heart conditions have very rarely been initiated by rheumatism acquired on active service. Among many cases of pneumonia there were no examples of myocarditis.

The special significance of diphtheria and nephritis as causes of cardiovascular disorders in military practice is discussed.

\section{REFERENCES}

Hill, I. G. W. and Dewar, H. A. (1945). Lancet, 2, 161.

Lewis, T. (1940). The Soldier's Heart and the Effort Syndrome : 2nd edition. Official History of the Great War: Medical Services, 3, 506.

Parkinson, J. (1916). Brit. Med. J., 2, 133.

Wood, P. (1941). Ibid., 1, 767. 